DOI: http://doi.org/10.21698/simi.2018.ab11

\title{
OBTAINING AND STUDY OF NEW ACTIVATED CARBONS FOR ECOLOGICALLY SUSTAINABLE TECHNOLOGIES
}

Tudor Lupascu, Mihail Ciobanu, Raisa Nastas, Oleg Petuhov

Institute of Chemistry of Academy of Sciences of Moldova, 3 Academiei Street, MD-2028, Chisinau, ichem@asm.md, lupascut@gmail.com, Republic of Moldova

Keywords: activated carbon, groundwater, pollutant removal, sulphide ions

\section{Introduction}

In the Republic of Moldova, $50 \%$ of groundwater is polluted by toxic compounds, such as sulphides, fluorides, fluorine, nitrites, nitrates, ammonium ions, heavy metals etc., and therefore this water does not meet the sanitary standards of drinking water. The use of activated carbons and catalysts obtained on the basis of these carbonic adsorbents for obtaining drinking water from groundwater has gained a lot of popularity lately. The results obtained by the Laboratory of Ecological Chemistry of the Institute of Chemistry of the Republic of Moldova showed that oxidized carbonic adsorbents, further impregnated with transition metal ions, especially with divalent copper, enhance the oxidation of sulphides to sulphates, sulphites and thiosulphates. This allows avoiding the formation of colloidal sulphur, and the catalysts obtained from activated carbons may be used longer in the process of obtaining drinking water from groundwater.

This research also presents the results of studies on the removal of heavy metal ions from groundwater, especially of bivalent iron and manganese. The paper as well shows the results obtained during the study of processes of regeneration of exhausted activated carbons, using usual thermal methods and microwaves.

\section{Materials and methods}

In this research we used industrial activated carbons, as well as carbons obtained in pilot conditions from the local raw material. In order to establish the mechanisms of pollutants oxidation were used such physical and physicochemical techniques, as the mass spectrometry, FTIR, nitrogen adsorption in gas phase, atomic spectroscopy, thermal analysis, chemiluminescence etc.

\section{Results and conclusions}

The results show that during the oxidation of sulphides using carbonic catalysts, this pollutant is mainly oxidized to sulphate. This may be explained by the fact that during the aeration process in aqueous medium, copper ions that are chemically bound to the carboxyl groups of activated carbons form free radicals that can oxidize sulphides from an oxidation degree of -2 to +6 .

The processes of removal of sulphides from groundwater were performed in dynamic conditions. It was found that upon the passing of approximately 1450 liters of water through the column filled with the adsorbent modified with copper ions $\mathrm{CAPrO} 36 \mathrm{Cu}$, 


\section{INTERNATIONAL SYMPOSIUM "THE ENVIRONMENT AND THE INDUSTRY", SIMI 2018, BOOK OF ABSTRACTS}

the adsorption/oxidation threshold was not reached and hydrogen sulphide was not found in the eluates.

The capacity of removing hydrogen sulphide from groundwater, performed under dynamic conditions as a ratio of the adsorbent volume and the volume of water passed through the column, equals to 1:58400 for the $\mathrm{CAPrO} 36 \mathrm{Cu}$ adsorbent, i.e. one volume of catalyst obtained from activated carbons can serve to obtain 58400 volumes of drinking water from the groundwater polluted with sulphides.

The activated carbons exhausted during the obtaining of drinking water were further regenerated using the usual thermal method and microwaves. The obtained results are shown in Tables 1 and 2.

Table 1. Structural parameters of activated carbons

\begin{tabular}{|c|c|c|c|c|c|c|c|}
\hline \multirow[t]{2}{*}{ Sample } & \multirow{2}{*}{$\begin{array}{l}\mathrm{S}_{\mathrm{BET}}, \\
\mathrm{m}^{2} / \mathrm{g}\end{array}$} & \multirow{2}{*}{$\begin{array}{c}V_{\mathrm{s}}, \\
\mathrm{cm}^{3} / \mathrm{g}\end{array}$} & \multirow{2}{*}{$\begin{array}{c}\mathrm{V}_{\mathrm{mi}} \\
\mathrm{cm}^{3} / \mathrm{g}\end{array}$} & \multirow{2}{*}{$\begin{array}{c}\mathrm{r}_{\mathrm{ef}}, \\
\AA\end{array}$} & \multirow{2}{*}{$\underset{\mathrm{kj} / \mathrm{mol}}{\mathrm{E}_{\mathrm{A}}}$} & \multicolumn{2}{|c|}{ After sorption } \\
\hline & & & & & & $\begin{array}{l}\mathrm{S}_{\mathrm{BET}}, \\
\mathrm{m}^{2} / \mathrm{g}\end{array}$ & $\begin{array}{c}\mathrm{V}_{\mathrm{s}} \\
\mathrm{cm}^{3} / \mathrm{g}\end{array}$ \\
\hline CAS-32 & 1605.8 & 0.867 & 0.639 & 6.20 & 16.36 & 1253.2 & 0.640 \\
\hline AG-3 & 941.5 & 0.657 & 0.251 & 5.89 & 17.28 & 779.0 & 0.419 \\
\hline
\end{tabular}

Table 2. Regeneration of activated carbons

\begin{tabular}{lccccc|ccccc}
\hline AC & \multicolumn{4}{c|}{ Thermal regeneration } & \multicolumn{5}{c}{ MW regeneration } \\
\cline { 2 - 11 } & $\begin{array}{c}\mathrm{T}, \\
{ }^{\circ} \mathrm{C}\end{array}$ & $\begin{array}{c}\mathrm{t}, \\
\min \end{array}$ & $\begin{array}{c}\mathrm{n}, \\
\%\end{array}$ & $\begin{array}{c}\mathrm{S}_{\mathrm{BET}}, \\
\mathrm{m}^{2} / \mathrm{g}\end{array}$ & $\begin{array}{c}\mathrm{V}_{\mathrm{s}}, \\
\mathrm{cm}^{3} / \mathrm{g}\end{array}$ & $\begin{array}{c}\mathrm{T}, \\
{ }^{\circ} \mathrm{C}\end{array}$ & $\begin{array}{c}\mathrm{t}, \\
\mathrm{min}\end{array}$ & $\begin{array}{c}\mathrm{\eta}, \\
\%\end{array}$ & $\begin{array}{c}\mathrm{S}_{\mathrm{BET}}, \\
\mathrm{m}^{2} / \mathrm{g}\end{array}$ & $\begin{array}{c}\mathrm{V}_{\mathrm{s}}, \\
\mathrm{cm}^{3} / \mathrm{g}\end{array}$ \\
\hline CAS-32 & 900 & 180 & 70 & 1298 & 0.67 & 500 & 20 & 81 & 1328 & 0.70 \\
\hline AG-3 & 900 & 180 & 88 & 819 & 0.43 & 500 & 20 & 86 & 945 & 0.54 \\
\hline
\end{tabular}

The analysis of results presented in Tables 1 and 2 show that the regeneration of activated carbons using microwaves is more efficient.

\section{Acknowledgments}

The research leading to these results has received funding from the MSCA-RISE action; project 734641 NanoMed, within the H2020 Marie Skłodowska-Curie Research and Innovation Staff Exchange Programme. 